Jair Leonardo Lopes, professor de direito penal Jair Leonardo Lopes na Faculdade de Direito da Universidade Federal de Minas Gerais - UFMG.

\title{
O crime e seu resultado na reforma penal
}

Honrado com o convite do professor Rogério Lauria Tucci para participar, como conferencista, deste I Ciclo de Estudos sobre o Direito e Processo Penal, que se realiza sob os auspícios do Instituto dos Advogados Brasileiros, cumpria-me escolher um tema acerca da reforma penal. Cada um de nós, que nos dedicamos ao estudo de determinado ramo da ciência jurídica, temos às vezes fixação intelectual em certos assuntos, que se transformam, não raro, em verdadeiras idéias obsessivas. Tais idéias, como se fossem travessos duendes, assaltam o nosso espírito, a cada momento, no correr de nossas leituras ou na vivência profissional dos casos concretos. Desde muito tempo, e foi a propósito de um caso concreto, o problema do resultado, em nosso direito penal, vem sendo objeto de minhas reflexões.

Vou descrever o caso concreto como ponto de partida para discussão da matéria. Aliás, o método do caso - muito adotado pelos americanos - vem sendo também utilizado por penalistas alemães, como Baumann e Wessels, este, como sabemos, já traduzido para o nosso idioma, graças aos serviços prestados à nossa cultura jurídica por este jovem e brilhante penalista, que é Juarez Tavares.

A dogmática deve servir à lógica, mas para ser útil deve solucionar os casos concretos. Por mais perfeita que seja uma construção lógica, se não servir à vida, não servirá também ao direito, por mais agradável que possa ser aos espíritos meramente especulativos.

Vamos ao caso

Na comarca de Congonhas do Campo, nos idos de 1965, fora denunciado e condenado por crime de curandeirismo (art. 284 do Código penal) José Pedro de Freitas, mais conhecido por Zé Arigó. Constou da sentença condenatória, dentre outras afirmações sobre a constância das práticas atribuídas ao réu, a de que "cerca de dois milhões de enfermos já foram atendidos por Arigó nesses últimos doze anos".

Ao lado dessa afirmação do juiz, despertou-me a atenção a circunstância de, a despeito da ampla publicidade realizada sobre o caso pela imprensa falada, escrita e televisionada, não ter aparecido qualquer vítima de dano à sua saúde em razão de atendimento pelo réu. Contudo, contra ele dizia-se que o crime imputado era de 'perigo abstrato' e que, em tais crimes, não se cogita do dano, nem se exige prova do perigo, porque este se presume em caráter absoluto.

O crime de 'perigo abstrato' seria, então, um crime sem resultado, assim como o chamado 'crime de mera conduta', que, segundo alguns, também não depende de resultado.

Esta colocação nunca satisfez ao meu espírito. Afinal, em face da sistemática de nosso Código, haverá mesmo crime sem resultado? Esta a indagação, que passei a fazer a mim mesmo, tendo em vista, inclusive, a doutrina segundo a qual o dano ao bem jurídico ou a sua exposição a perigo constitui elemento essencial ao aperfeiçoamento da conduta típica.

Por isso, pareceu-me que caberia também indagar se foi feliz a comissão revisora do Anteproje- 
to de lei modificativo da parte geral do Código penal de 40, quando resolveu mudar o tempo do verbo 'depender' no art. 13 do Anteprojeto, fazendo constar "o resultado, de que dependa a existência do crime", em lugar de "o resultado, de que depende a existência do crime" , ... redação primitiva e que reproduzia, nesta parte, a do art. 11 do Código penal vigente.

O Instituto de Ciências Penais do Rio de Janeiro, que deu à comissão revisora uma das mais relevantes contribuições, fazendo-Ihe diversas sugestões, propôs, como também o Dr. Sílvio Teixeira Moreira, a redação adotada, isto é, a modificação do tempo do verbo, ao argumento de que nem todo crime depende de resultado.

Outros, porém, sugeriram a manutenção do artigo 13, lembrando-me, dentre esses, o Dr. Menna Barreto e, dentre órgãos, que mandaram sugestões, a Procuradoria Geral de São Paulo e a Universidade Federal de Mato Grosso.

Everardo da Cunha Luna, lautor da tese de concurso intitulada $O$ resultado no direito penal. São Paulo, Bushatsky, 1976), em excelente trabalho intitulado 0 crime, no Projeto de lei de 1981, publicado na Revista do Conselho Penitenciário do Distrito Federal. 18 (43), opinara que mais correta era a redação primitiva do art. 13, embora seja dos que entendem que há crime sem resultado. Contudo, fazia aquela opção dando razões de ordem lingüistica e referentes à própria inspiração do texto do direito pátrio no art. 40 do Código italiano, que emprega a expressão 'da cui dipende' ao invés de 'dipenda'. E chegou a supor que afastada não estivesse "a possibilidade de um erro datilográfico, que passou despercebido aos eminentes membros da Comissão".

Em verdade, não houve erro datilográfico, a comissão revisora, por maioria, resolveu mesmo mudar o tempo do verbo 'depender', considerando meIhor a forma adotada, ao argumento de que há, também, crime sem resultado.

A primeira vista, pode parecer sem importância a controvérsia sobre a existência, ou não, de crime sem resultado. Entretanto, quando se aprofunda na análise do fato punivel e no estudo da sistemática do nosso Código penal, chega-se à conclusão, como observa Everardo na obra citada, que o resultado "mantém relações com todos os institutos jurídico-penais. Relações, como vimos nos capítulos antecedentes - diz ele - , com o problema da aplicação da lei penal, no tempo e no espaço; com o conceito do crime e a classificação das infrações penais; com a injuridicidade, a tipicidade e o bem jurídico; com os elementos materiais do crime, a ação e a omissão, a causalidade, o instrumento, o tempo, o lugar; com os elementos subjetivos do crime, o dolo, a culpa, o motivo, o fim, a consciência do ilícito. Mantém relações, também, o problema do resultado, com as circunstâncias e as formas do crime" (p. 101).

Por sua vez, Manoel Pedro Pimentel (Crimes de mera conduta. 2. ed. São Paulo, Ed. Revista do Tribunais/Ed. Universidade de São Paulo, 1968. p. 45), após referir-se à "oposição entre evento jurídico e evento natural", observa que "A disputa que se trava entre os penalistas, situados em cada uma destas duas posiç̃es antagônicas, não é nova. Nem se há de supor que a discussão seja meramente acadêmica. Todos os que trataram do assunto com certa profundidade confessam que este problema é o centro de gravitação de todo o Direito Penal". "Pensamos - diz o professor paulista - que não há exagero nesta afirmativa, bastando dizer que a conceituação do evento interessa diretamente à própria teoria geral do crime e regula a função preventiva da pena, relacionando-se, deste modo, também à Política Criminal."

Mas, afinal, o que se deve entender por resultado, do ponto de vista jurídico-penal? A elaboração de um conceito jurídico, ainda que tenha como suporte um fato do mundo físico, está sujeita à valoração própria do mundo do dever ser. Daí, não poder o conceito de resultado ser um conceito naturalístico, já que situado no plano normativo do tipo, que é a técnica de proteção de bens ou valores, mediante a descrição daquelas ações ou omissões, que possam vir a lesar ou expor a perigo o objeto da proteção, sujeitando à pena os seus autores

Para mim, o conceito de resultado deve ser buscado no direito positivo em vigor. Conquanto possa, às vezes, ter um suporte fático no mundo físico, trata-se de um conceito normativo, cuja elaboração pertence à dogmática jurídico-penal e esta se constrói sobre o direito positivo vigente em cada pais.

Não é por acaso que os alemães, em suas obras, à exceção de Jescheck, restringem a bibliografia aos seus próprios compatriotas. Isso levou Soler, no prefácio da tradução da obra de Beling, a fazer sobre os tratadistas alemães a seguinte observação: "Só uma censura grave se lhes pode formular seu provincianismo; seu total desconhecimento da produção estrangeira, pois parecem desconhecer até a existência de figuras tão egrégias como a de Carraras."

Entre nós, Lydio Machado Bandeira de Mello, a propósito do Tratado de Von Liszt, diz ser "uma exposição objetiva do direito penal alemão em vigor no tempo em que o escreveu" e que "não cita autores estrangeiros no texto da obra"; sendo que, ao tratar da legítima defesa, "não cita um penólogo es- 
trangeiro". E continua o mestre mineiro, ironicamente, "expõe o assunto todo, como se a Legítima Defesa fosse uma descoberta da Alemanha e só existisse em seu país"; acabando por aconselhar: "Pois então façamos o mesmo, professores e alunos de Direito no Brasil: sistematizemos o nosso Direito Penal (que, unido ao Português, e encarado desde os seus primórdios, é o mais belo e interessante do Mundo) e criemos uma ciência e uma arte (ou jurisprudência) penais genuinamente brasileiras" (Manual de direito penal. Belo Horizonte, 1953. v. 1, p. 169).

A meu ver, a atitude dos penalistas germânicos talvez possa justificar-se, em parte, pela fidelidade ao método próprio da ciência penal, cujo objeto de estudo, como ensinou o nosso Aníbal Bruno, é uma norma de comportamento, a norma jurídico-penal. Partindo das normas legais vigentes, para sobre elas construir um corpo de doutrina, descobrindo e formulando conceitos, organizando-os, dando-Ihes unidade, a dogmática só tem um caminho natural, que é o lógico (Direito penal. t. 1, p. 41).

E este caminho há de ser percorrido sobre a legislação de cada país, o que não exclui, naturalmente, a obra de comparação e mesmo os subsídios da doutrina estrangeira, sobretudo quando, nos textos da legislação alienígena, são encontradas as fontes do próprio direito nacional ou normas iguais às nossas.

Segundo o art. 11 do Código penal vigente, "O resultado, de que depende a existência do crime, somente é imputável a quem Ihe deu causa". Ora, se a existência do crime depende do resultado, há uma relação necessária entre a existência do crime e o resultado, de tal modo que aquele não pode existir sem este, sob pena de desfazer-se a relação de dependência.

Aliás, esta interpretação condiz com a sistemática do nosso Código que tanto considera o resultado essencial ao crime, que não pune a tentativa quando, por ineficácia absoluta do meio ou por absoluta impropriedade do opjeto, é impossível consumar-se o crime lart. 14 do Código penal e 17 do Anteprojetol. Por outro lado, exige-se, para configuração do dolo, que o agente tenha querido o resultado (art. 15, do CP e 18 do Anteprojeto) e, para a configuração da culpa, que por imprudência, negligência ou imperícia, tenha dado causa ao resultado (art. 15, II, do CP e 18, II, do Anteprojeto).

Na construção legal da tentativa, está implícita a idéia do resultado, pois só com ele verifica-se a consumação tanto que se o agente voluntariamente "impede que o resultado se produza", só responde pelos atos já praticados lart. 13, do Código penal e 15 do Anteprojeto). Além disso, a impunibili- dade do "ajuste, de determinação ou da instigação e o auxílio, se o crime não chega, pelo menos, a ser tentado", a meu ver, também se explica pela ausência do resultado (art. 27 do CP e 31 do Anteprojeto).

Na fixação do lugar do crime, recorre-se à idéia do resultado (art. $4{ }^{\circ}$ do Código penal e 6. do Anteprojeto revistol, sendo que o Anteprojeto se vale do resultado na definição do "tempo do crime" (art. 6. do Anteprojeto e $4^{\circ}$. do Anteprojeto revisto) e no art. 19 , ao afastar os casos de responsabilidade objetiva, só permitindo a agravação especial da pena pelo resultado quando o agente o houver causado, pelo menos, culposamente.

No erro de execução, pode determinar-se a responsabilidade por culpa ou por dolo em razão do resultado alcançado pelo agente lart. 54 do Código penal e 74 do Ánteprojetol.

Segundo Heleno Cláudio Fragoso, tendo em vista as disposições contidas no direito italiano e no direito brasileiro, há ainda um valioso argumento a reforçar o entendimento de que não há crime sem resultado. Os artigos 40 e 43 do Código Rocco e os artigos 11 e 15 de nosso vigente diploma penal, ao tratarem da relação de causalidade e da culpabilidade, parecem deixar claro que a todo crime é necessário um resultado ou um acontecimento exterior à conduta. A Exposição de Motivos de nosso Código (§ 13) - diz Heleno - esclarece o pensamento do legislador a respeito, de forma a excluir qualquer dúvida" (Conduta punivel. São Paulo, Bushatsky, 1961. p. 71-3, n. 26).

De fato, conforme a Exposição de Motivos, "O projeto acolhe o conceito de que 'não há crime sem resultado.' Não existe crime sem que ocorra, pelo menos, um perigo de dano e sendo o perigo um 'trecho da realidade' (um 'estado de fato' que contém as condições de superveniência de um efeito lesivol, não pode deixar de ser considerado, objetivamente, como 'resultado', pouco importando que, em tal caso, o resultado coincida, cronologicamente, com a ação ou omissão" (item 13 da Exposição do ministro da Justiça).

Nelson Hungria, o mais autorizado comentarista de nosso Código penal, diz que: "Segundo a teoria realistica, decididamente aceita pelo nosso Código, não é concebivel o crime sem que haja uma atuação voluntária, acarretando, pelo menos, uma situação de perigo, uma probabilidade de dano a um bem jurídico penalmente protegido" (Comentários ao código penal. v. 1, t. 2, p. 71, n. 62).

No meu entender, segundo a natureza do resultado, os crimes podem ser de dano ou de perigo. O crime de dano ocorre quando a ação acarreta a perda, a diminuição ou a restrição de um bem ou 
valor jurídico. O crime é de perigo quando a ação cria a probabilidade de dano a um bem ou valor protegido pela norma.

O professor Basileu Garcia, quando analisa o evento integrante do elemento objetivo da infração, diz referindo-se aos delitos "há os que se consumam desde que determinem um perigo, ainda que não advenha a lesão. Outros, entretanto, se perfazem através da ofensa positiva a um bem jurídico ou a um interesse legalmente protegido" (Instituições de direito penal. v. 1, t.2, p. 203 , n. 64).

Não é outra a lic̣ão de Aníbal Bruno, a saber: "O resultado que integra a ação ou omissão criminosa pode apresentar-se sob a forma de um dano ou de um perigo. Os 'crimes de dano' só se consideram consumados quando ocorre uma lesão efetiva de um bem ou interesse jurídico. Nessa categoria se incluem a maioria dos fatos delituosos - o homicídio, as lesões corporais, o furto, o roubo, o dano. Os 'crimes de perigo' não reclamam para que se julguem perfeitos um dano efetivo. Basta para configurá-los a probabilidade de dano. Nessa probabilidade de dano está a definição de perigo" (Direito penal. s.I., Ed. Nacional de Direito, 956. t.2, p. 602).

Galdino Siqueira afirma que "todo crime exige, pois, um resultado no mundo exterior, e, por isso, falar em crime sem resultado é uma contradictio in adjecto". E explica o antigo mestre que foi preconizada na Alemanha a distinção entre crimes que produzem um resultado e meros crimes ou delitos de atividade, que não produzem resultado nenhum. Substancialmente, é a mesma distinção assinalada por outros entre crimes materiais e crimes formais. (Tratado de direito penal). São Paulo, José Konfino, 1947. v. 1, p. 273).

João Mestieri situa muito bem o problema quando escreve que "Alguns autores relacionando o conceito de resultado ao de realização material, de câmbio no mundo exterior, inclinaram-se no sentido de admitir delitos sem resultado, delitos de simples atividade. Sem razão. Nesses delitos, o desenvolvimento da própria ação incriminada é suficiente para o cumprimento do tipo. O momento consumativo situa-se, então, naquele instante em que a conduta incriminada se perfaz, não se fazendo necessário qualquer evento externo. Mas ainda nestes casos há resultado, no sentido jurídico. Veremos ao tratarmos do tipo penal (adiante § 18) que o legislador ao atribuir a determinado injusto o caráter de criminal, descrevendo-o, e distinguindo-o de outros ilicitos, fá-lo a fim de proteger determinado bem ou interesse do dano efetivo ou mesmo de simples estado de periclitação" (Teoria elementar do direito criminal. Rio de Janeiro, 1971. t.1, p. 232, § 13).
Entre os autores italianos, em cujo Código penal (art. 40) o nosso legislador foi buscar inspiração, predomina o ponto de vista de que não há crime sem resultado. Maggiore considera "absurdo falar de delitos sem resultado. Somente existem delitos com resultado imediato ou mediato, próximo ou remoto, que têm por conseguinte um iter fracionável e um iter que, pela estreita adesão entre a causa e o efeito, aparece como não divisivel". E mais adiante acrescenta o mesmo penalista: "Outra questão que se tem convertido entre os penalistas em uma espécie de 'campo de Agramante' é a seguinte: existem delitos sem resultados? Na dogmática alemã prevalece a resposta afirmativa" - diz ele. "Ao lado dos delitos com resultado reconhecem a categoria dos delitos chamados de ação ou delitos de pura atividade. Exigir-se-ia nos primeiros, além do movimento corporal, a verificação do resultado exterior em que se realiza o delito-tipo; nos segundos bastaria o simples movimento corporal, em que se esgota o delito-tipo, sem depender da modificação do mundo exterior; tais seriam, principalmente, os delitos chamados de palavra (falso testemunho, juramento em falso, calúnia, injúria, etc). Na literatura jurídico-penal italiana, a opinião dominante tem-se mostrado contra a categoria dos delitos sem resultado, ao admitir que este, ainda que não seja concebível de uma maneira natural, sempre existe em sentido juridico". Conclui o mestre de Palermo, com certa ponta de malícia, que se tem "excogitado para reforçar a teoria dos delitos sem resultado uma suposta classe de delitos inofensivos, tais que seu resultado não ofende nenhum bem nem interesse, nem constitui dano nem perigo. Francamente, se existesse em realidade este gênero de delitos inócuos, mereceria ser castigado com penas... inofensivas!" (Derecho penal. Bogotá, Editorial Temis, 1954. v. 1, p. 361-3).

No mesmo sentido, Giulio Battaglini, para quem "não há delito sem evento. No sistema do direito positivo italiano, não se concebe conclusão diversa; isso porque o artigo 40 do Código penal condiciona a existência de qualquer crime a um evento material, danoso ou perigoso, devendo, por conseguinte, basear-se sobre esta concepção a construção da teoria do delito. Somos, portanto, contrários de jure conditio, à admissão de delitos denominados de 'mera conduta ou sem evento'.

O citado penalista peninsular enfrenta a questão dos crimes omissivos, escrevendo: "Sustentouse faltar no delito omissivo próprio" ( v. g. omissão ou recusa de ato oficial: artigo 328, do Código penal italiano; omissão de comunicação de crime de ação pública por parte de quem exerça profissão sanitária: artigo 365 do mesmo diploma legal), um resultado: vale dizer, segundo nossa concepção, um 
evento em sentido formal. Tal não nos parece exato. Realmente, até na pura omissão existe resultado: um resultado negativo. Este também constitui um quid novi no mundo externo, ou seja, uma modificação anteriormente inexistente. De outra parte não padece dúvida de que o delito de pura omissão, assim como o de ação, implique em investida contra interesses juridicamente tutelados (evento substancial). (Direito penal. Trad. de Paulo José da Costa Júnior e Ada Pelegrini Grinover. São Paulo, Saraiva, 1964. p. 175)

A propósito do crime omissivo, Alcidez Munhoz Netto, em recente comunicação ao XIII Congresso Internacional de Direito Penal, apresentada no Colóquio de Direito Penal do Rio de Janeiro, assim discorreu: "Não é em função da mera desobediência à vontade estatal que certas omissões são penalmente sancionadas; são incriminadas à vista da preocupação da ordem jurídica em conjurar situacões de que possa advir o sacrifício de determinados valores. Em princípio, a omissão só incide em pena criminal quando objetivamente se reúnam condições de alta probabilidade de lesão ao bem jurídico merecedor de tutela penal. Tal situação de perigo é que legitima a imposição do dever de agir. Com efeito, a impossibilidade do incapaz, quando exposto à própria sorte, de defender-se dos riscos para a sua saúde, é que determina o dever de não abandonálo, da parte de quem sobre o mesmo exerce autoridade ou está incumbido de sua guarda ou cuidado (art. 133); o encontrar-se a criança abandonada, a criança extraviada, a pessoa inválida ou a pessoa ferida, ao desamparo ou em grave ou iminente perigo, é que acarreta o dever de prestar-Ihes assistência (art. 135). Portanto, a tipicidade dos crimes omissivos próprios requer a ocorrência de fatos de que deflua o dever de agir. Tal dever é, assim, imposto em função do perigo ao bem jurídico. Tanto isto é certo, que a omissão só é típica se o omitente possuía o poder de fato de atuar evitando a lesão. Se faltar a possibilidade de realizar uma ação que impeça a lesão, não haverá omissão adequada ao tipo penal. Não são, por conseguinte, de simples desobediência, os crimes omissivos próprios. Constituem-se, antes, em crimes de perigo, incriminados em função do objetivo de preservar bens jurídicos fundamentais."

Parece que nem mesmo entre os alemães, que preconizaram a distinção entre crimes com resultado e crimes sem resultado, alguém negue que "o crime, para aperfeiçoar-se, exija um dano ou a sua probabilidade. Evidentemente, o dano ou a sua probabilidade não pode ser conseqüência de forças da natureza não desencadeadas por ação humana. Entretanto, não se pode enfatizar o 'desvalor da ação' , como se fosse independente do 'desvalor do resulta- do'. Como ensina Jescheck, "na conduta que põe em perigo o objeto do ataque radica 'o desvalor da ação' do fato punivel. O direito penal leva a cabo a proteção de bens jurídicos procurando fazer com que a vontade dos cidadãos se ajuste às exigências do ordenamento jurídico" (Tratado de derecho penal. Trad. de F. Muñoz Conde. Barcelona, Bosch, 1981. v. 1, p. 10-1, n.2, § 1).

No mesmo sentido, Johannes Wessels, para quem "a tarefa do Direito Penal consiste em proteger os valores elementares da vida comunitária no âmbito da ordem social e garantir a manutenção da paz jurídica. Como ordenamento protetor e pacificador serve o Direito Penal à 'proteção dos bens jurídicos e à manutenção da paz pública'. "Por bens jurídicos" - continua o mesmo penalista "designam-se os bens vitais, os valores sociais e os interesses juridicamente reconhecidos do indivíduo ou da coletividade, que, em virtude de seu especial significado para a sociedade, requerem proteção jurídica. Bens jurídicos do indivíduo são, por exemplo, a vida, a integridade física, a liberdade pessoal, a honra, a propriedade, o patrimônio, etc. $(=$ bens juridicos individuais). Bens jurídicos da coletividade são, por exemplo, a constituição do Estado e sua ordem democrática e liberal, a conservação dos segredos de Estado, administração da justiça, a incorruptibilidade dos funcionários, a segurança do tráfego monetário, a fidelidade dos documentos na relação jurídica, etc. (= bens jurídicos universais). (Direito penal. Tradução de Juarez Tavarez. Porto Alegre, 1976. Parte geral, p.3, § 1-1-21.

No particular, a posição de Claus Roxin não é diferente, pois diz "que em cada situação histórica e social de um grupo humano os pressupostos imprescindiveis para uma existência em comum se concretizam em uma série de condições valiosas, das quais, a vida, a integridade corporal, a liberdade de atuação ou a propriedade, todo o mundo as tem presentes; em uma palavra: os chamados bens jurídicos; e o Direito Penal tem que assegurar estes bens jurídicos punindo sua lesão em determinadas condições" (Problemas básicos del derecho penal. Trad. de Diego Manuel Luzõn Peña. Madrid, Reus. S.A., 1976. p. 21).

Entretanto, onde parece-me residir a contradição na doutrina é no admitir-se que não pode haver crime sem o dano ao bem jurídico ou a sua exposição a perigo e, em seguida, dizer-se que há crime sem resultado.

Como se chamaria, então, a esse dano ou a essa probabilidade de dano ao bem jurídico, senão resultado? O professor Everardo da Cunha Luna alude a um dano real e a um dano ideal, o dano real, segundo ele, 'consiste no dano do resultado' e o 
ideal é o 'dano da ação'. Com essa distinção o eminente professor do Recife admite a existência de crime sem resultado, embora a meu ver o dano ideal 'ínsito na ação' a que se refere seja, em verdade, a probabilidade do dano (= a perigo), que é o mínimo que se pode admitir para que uma conduta seja típica.

Aliás, Maurach, após reproduzir a distinção entre 'delitos de atividade' e 'delitos de resultado', em função, segundo ele, do grau de vinculação entre ação e resultado, reconhece que "em rigor lógico esta distinção não é feliz. Efetivamente - prossegue o mestre de Munich - todo delito consumado tem um resultado, constituído pelo cumprimento do tipo; a própria conduta do autor implicita na ação leva consigo o resultado relevante para o tipo (Tratado de derecho penal. Tradução de Juan Cordoba Roda. 2 ed. Barcelona, Ariel, 1962. p. 276, § 20-III)

Pouco importa que o dano ou o perigo se destaque ou não da ação ou omissão - o que importa é saber se a conduta realiza ou não o tipo, lesando ou expondo a perigo o objeto da proteção.

Pode-se até falar em crime de mera conduta ou em crime de perigo abstrato, desde que se não admita crime sem resultado. A própria posição sistemática de tais crimes, sob a rubrica de determinados títulos da parte especial do Código penal brasileiro, significa que ofendem ou ameaçam de ofensa o bem ou valor objeto de proteção naquele título ou capítulo.

Assim, por exemplo, o fato de alguém entrar ou permanecer, clandestina ou astuciosamente, contra a vontade expressa ou tácita de quem de direito, em casa alheia ou em suas dependências, não há dúvida que impõe à 'pessoa' (título I) uma restrição à sua 'liberdade' (capítulo VI) de manter-se tranqüilo em seu domicilio, que é inviolável (seção II), constituindo garantia individual (Constituição da República. art. 153, § 10), objeto de proteção, sob ameaça de pena, no artigo 150 do Código penal.

Admitir-se crime sem resultado equivale a dizer-se que há um tipo cuja realização não lesa nem expõe a perigo qualquer bem ou valor. O tipo não é obra de mera sofisticação legislativa, nem existe para si mesmo, ele é sempre uma técnica de proteção de bens e valores da vida individual ou coletiva, considerados indispensáveis à convivência humana.

Valho-me, aqui, de uma passagem de Francisco de Assis Toledo, para quem "a criação legal de figuras delitivas que não impliquem lesão real, ou potencial, a bens jurídicos seria, com efeito, a admissão de um sistema penal que pretendesse punir o agente pelo seu modo de ser ou de pensar. Apesar disso, não se pode negar a existência de resíduos dessas figuras em certos tipos penais, ou em alguns códigos vigentes. A punicão da tentativa impossívèl, contemplada em vários países sul-americanos (não no Brasil) e na atual legislação penal alemã (StGB, § 23, III) é um exemplo de punição de ânimo. Os denominados crimes de perigo abstrato são outro exemplo (Princípios básicos de direito penal. São Paulo, Saraiva, 1982. p. 19).

Segundo Bettiol, "na contenda que se trava em torno da noção do crime, isto é, se ela deve ser constituída pela lesão de um bem jurídico ou pela violação de um dever, deve-se dar prevalência a lesão do bem jurídico porque a noção do dever não pode possuir uma autonomia funcional. O dever especifica-se somente em contato com os interesses protegidos e destes adquire vigor e relevo" (Direito penal. Trad. de Paulo José da Costa Júnior e Alberto da Silva Franco. São Paulo. Ed. Revista dos Tribunais, 1966. v.1, p. 218-9)

Zaffaroni, criticando as tentativas de prescindir do conceito de bem jurídico, ensaiadas pelo direito penal do nacional socialista com a Escola de Kiel, escreve: "o injusto concebido como lesão a um dever é uma concepção positivista extrema, que resulta de uma interrupção na análise, antes de chegar à essência deste aspecto do injusto: é a consagração irracional do dever pelo dever mesmo. Certamente, sempre há no injusto uma lesão ao dever, porém se lesa ao dever (se viola a proibição), porque com esta conduta se afeta o que a norma tutela. Ficarmos sem averiguar o porquê e sem investigar a lesão é interromper arbitrariamente a análise e em nosso sistema isso não é possível: devemos fazê-lo porque se a ação não atinge a moral ou a ordem públicas nem prejudica a terceiros, deve permanecer impune, por expressa disposição constitucional".

De fato, seria rematado absurdo punir-se uma conduta que não produzisse qualquer resultado juridicamente relevante; consiste em um dano ou, pelo menos, na sua probabilidade. Por isso, a meu ver, não se pode conceber um 'tipo' que institua uma presunção absoluta de perigo. Nos chamados crimes de perigo abstrato, em verdade, o perigo é concretíssimo, porque está ínsito na própria descrição típica.

Veja-se, por exemplo, o crime de 'corrupção ou poluição de água potável'; a descrição típica é: "corromper ou poluir água potável, de uso comum ou particular, tornando-a imprópria para o consumo ou nociva à saúde" (art. 271). Ora, quem, mediante sua corrupção ou poluição, torna a água imprópria para consumo ou nociva à saúde, evidentemente, cria uma situação de perigo para a saúde pública, porque há grande probabilidade de dano pela sua ingestão, já que de uso comum ou particular. E tanto 
é provável o dano que o legislador chegou a prevêlo, mandando aplicar a pena aumentada de metade se resulta lesão corporal grave, e em dobro, se resulta morte (art. $285 \mathrm{c} /$ art. 258).

Mesmo a simples 'infração de medida sanitária preventiva', prevista no art. 268 , cuja ação consiste na inobservância de uma 'determinação de poder público', a pena é cominada porque a 'determinação do poder público' é destinada 'a impedir introdução ou propagação de doença contagiosa' e não há dúvida de que quem infringe tal determinação, que visa a impedir a introdução ou propagação da doença, cria inequívoca situação de perigo para a saúde pública, tornando provável a 'introdução ou propagação' da doença contagiosa.

Como se vê, os fatos, considerados pela doutrina como crimes de perigo abstrato, quando não têm o perigo como elemento integrante do tipo (por ex. adulterar substância alimentícia, 'tornando-a nociva à saúde' - art. 272; entregar a consumo substância alimentícia ou medicinal 'avariada' - art. 279), pelo menos o contém, de modo implícito, na própria conduta descrita, cuja realização encerra a probabilidade do dano, segundo a experiência.

E quando o perigo não esteja ínsito na própria descrição típica, a sua presunção não pode ser absoluta e tem-se que admitir prova em contrário, sob pena de consagrar-se a punição pela simples prática de determinada ação, ainda que dela jamais possa advir sequer a probabilidade do dano ao objeto jurídico da proteção.

Assim, no caso exposto no início, relativo ao crime de curandeirismo, o perigo só pode ser presumido juris tantum, isto é, até prova em contrário, sob pena de punir-se por uma ação que não encerra sequer a probabilidade de dano. O tipo não contém, em si mesmo, a descrição de ação que seja necessariamente perigosa; e, no caso concreto, não obstante sua repetição milhares de vezes, segundo a sentença, não adveio o dano, o que afastava o juízo sobre sua probabilidade, que poderia configurar o perigo.

Ora, sem dano e sem a sua probabilidade, como sustentamos, não é possível punir-se, porque, segundo o nosso Código, a existência do crime depende do resultado. Por isso, a orientação adotada na redação do artigo 13 do Anteprojeto do Código penal, antes da revisão, consagrava doutrina mais liberal e consentânea com a estrutura do elemento psicológico (art. 18), com a definição do crime impossível (art. 17), com o dispositivo sobre o arrependimento eficaz (art. 15) e com as normas sobre o tempo e lugar do crime.

Além do mais, a partir do momento que se ve- rifica, na realidade da vida, um dano a um bem ou valor ou sua exposição a perigo é que o direito penal se interessa pelo fato. A ação pura e simples, que não consiste em um perigo para um bem ou valor ou que não produza um dano, é indiferente, pelo menos, para o nosso direito penal.

Falou-se, na doutrina, em desvalor da ação como sendo o decisivo para o direito penal. Entretanto, a ação só é desvalorada porque produz um dano ou cria uma situação de perigo para um bem ou valor, objeto de proteção jurídica. É certo que a qualidade e quantidade da pena não dependem exclusivamente do resultado, mas, sem que este seja, pelo menos, provável, não pode haver pena. Tanto que, em nosso Código penal le também no Revisto Anteprojeto Modificativo da sua parte Geral - art. 17), a ação, por mais censurável que seja, não será punível se era inidônea a produzir o resultado juridicamente relevante (veja-se a prática abortiva na muIher que não está grávida ou os disparos sobre um corpo sem vida).

Cerezo Mir, discípulo proclamado por Welzel, na tradução da obra do seu mestre, O novo sistema do direito penal - uma introducão à doutrina da ação finalista, em nota de n. 10 , à página 44 , escreveu "não me parece viável, sem embargo, excluir o resultado do tipo do injusto. O injusto criminal só fica plenamente 'constituído' quanto ao desvalor da ação se acrescenta o desvalor do resultado". E prossegue "se o injusto criminal ficasse plenamente constituído com o desvalor da ação, olvidar-se-ia que este só pode fundamentar-se em referência à lesão do bem jurídico, quer dizer ao desvalor do resultado. A função ético-social do direito penal consiste no fomento do respeito aos bens jurídicos, por verse nele a melhor garantia de sua integridade".

É certo que o dano ou sua probabilidade, como um fato da natureza, é também irrelevante, do ponto de vista jurídico-penal. Mas a própria indagação sobre a autoria do fato só interessa se ele consistiu em ataque a um bem ou valor.

Dir-se-á, talvez, que não haveria como identificar-se este ataque ou agressão ao bem ou valor, quando consistir em uma omissão ou em um crime dos chamados de mera conduta.

A verdade, porém, é que em tais casos não deixará de haver um suporte fático para a imputação, consistente, por exemplo, no achar-se em uma via pública uma pessoa ferida, ao desamparo ou em grave e iminente perigo e alguém não lhe ter prestado socorro (art. 135); ou, em havendo casos de doença de notificação compulsória, em determinada localidade, deixar o médico de comunicar o fato à autoridade pública (art. 269). A omissão de ambos deixa de impedir a probabilidade do dano à saúde, 
respectivamente, individual ou pública. Na violação de domicílio, a presença de alguém na casa alheia, nas circunstâncias do. artigo 150, constitui um ataque inequívoco à liberdade do indivíduo dentro de seu domicílio, onde o espaço lhe é reservado, inclusive por garantia constitucional.

Neste ponto, é mais uma vez pertinente a lição de Maurach, segundo a qual resultaria errôneo negar, de plano, nos próprios delitos de omissão a existência de um resultado típico; sua problemática é a mesma que a dos delitos de pura atividade. A importância desta distinção aparecerá na teoria da tentativa. 'Resultado', no sentido do $§ 138$, é a omissão da denúncia de um delito capital cuja iminente produção é conhecida pelo autor (ob. cit., vol. II § 45, III A, p. 270-271). No mesmo sentido Gallas ( $\mathrm{La}$ teoría del delito en su momento actual. Tradução de Cordoba Roda. Barcelona, Bosch, 1959. p. 20).

Afinal, o que é, pois, permanente e deve ser o ponto de partida é a ocorrência de um dano ou da exposição a perigo de um bem ou valor da vida individual ou coletiva por meio de uma ação ou omissão voluntária. Isso é o proibido e somente para o proibido é que se procura uma justificação. O dano ou a exposição a perigo constitui uma realidade, que ficou sendo, e continuará a ser, quer a conduta seja considerada lícita ou ilícita. O dano ou a exposição a perigo não se confunde com a antijuridicidade. A morte é sempre a eliminação de uma vida humana; a subtração de uma coisa alheia é sempre uma diminuição do patrimônio de outrem. O morto não ressuscitará, ainda que a morte tenha sido justificada pela legítima defesa, nem o patrimônio deixará de ficar diminuído pelo fato de subtração ter ocorrido por ação praticada em estado de necessidade. Logo, a lesão ou a exposição a perigo de um bem ou valor não constitui, por si mesma, a antijuridicidade. A lesão de bens jurídicos protegidos penalmente não é um nullum - segundo Baumann " ao contrário, representa para nós - diz ele - o motivo para investigar esta conduta em sua antijuridicidade e examinar se existe realmente um injusto penal" (ob. cit. p. 160).

Mas aqui começa uma outra história, complicada e controvertida, das relações entre os elementos do fato punivel, que não lhes posso contar, nesta oportunidade, sem abusar, ainda mais, da bondade e tolerância de todos. 